American Journal of Applied Sciences 9 (2): 186-195, 2012

ISSN 1546-9239

(C) 2012 Science Publications

\title{
The Influences of Connectors and Adaptors to Fiber-To-The-Home Network Performance
}

\author{
Mohammad Syuhaimi Ab-Rahman, Mastang and Kasmiran Jumari \\ Department of Electrical, Electronics and Systems Engineering, \\ Faculty of Engineering and Built Environment, \\ University Kebangsaan Malaysia, 43600 UKM Bangi, Selangor, Malaysia
}

\begin{abstract}
Problem statement: The reliability of the entire communications network was dependent on the reliability of each single element. Connector was important devices that can affect the performance of the fiber communication. There were a large number of issues that affect the performance of fiber optic connectors in today's networks. These factors were increasingly as data rates, the number of wavelengths and transmission distances continue to escalate. Approach: Therefore this study was carried out to test on the influence of connectors and adapters to the performance of the optical network. Initially the actual attenuation of connector and adaptor were tested by using multifunction loss tester. The first two $1 \mathrm{~m}$ corning optical fibers with a connector at each end are measured. Then, both the $1 \mathrm{~m}$ corning optical fibers were joined together by an adaptor and connected to the Multifunction loss tester. Three types of wavelength are used as the source to test the attenuation of the fiber which is $1310,1490-1550 \mathrm{~nm}$. In order to measure the Bit Error Rate (BER) and the power loss in optical fiber communication, a simple simulation was carried out by using software opti sys. Results: The attenuation on the connector was caused mainly by existence of impurities in the connector, less perfect connection, scattering of beam and others. These causes the parameter such as power received, Q-factor, minimum BER and also the eye-height to change. Changes in these parameters also affect the performance at the user end. It was very critical that causes of attenuation to be eliminated. Conclusion/Recommendations: From the result it can be concluded that, the greater the attenuation, the greater the decrease in power received. It also affects the Q-factor of the system where as the attenuation increase, the maximum Q-factor decreases. As for the minimum BER, minimum BER changes as the attenuation increase initially, after a maximum value it decreases as the attenuation increases.
\end{abstract}

Key words: Connector attenuation, connector effect, connector reliability, adaptor effect, q-factor decrease, attenuation increase, maximum value, optical energy, scattering attenuation, caused mainly

\section{INTRODUCTION}

FTTH network uses optical fiber as the medium cable for signals transmission to users. Before optical fiber is implemented into networks, telephony copper cable is used to carry signals generated by telephony devices. The analog signal technology only capable to send signals with a small capacity with the implementation of optical fiber, multiple signals can be transmitted in a swift and at once. This provides the possibility for users to employ the internet and video and et cetera services with more ease and at a faster speed. This is due to optical fiber's capability that carrying the data signals at a speed exceeding 2.5 Gigabits per seconds compared to the speed of the signals carried through copper cables which is 1.5 Mbps. FTTH is desirable because it can carry highspeed broadband services integrating voice, data and video and runs directly to the junction box at the home or building. For this reason it is sometimes called Fiber To The Building, or FTTB. Traditional copper telephone wires carry analog signals generated by telephone equipment, including fax machines. Analog technology is by nature a less precise signaling technology than digital technology. Though multiplexing has allowed digital signals to be transmitted across multiple channels over copper lines, fiber optic cable is superior for relaying these signals and allows for faster transfer rates and virtually unlimited bandwidth. This opens the door to better

Corresponding Author: Mohammad Syuhaimi Ab-Rahman, Department of Electrical, Electronics and Systems Engineering,

Faculty of Engineering and Built Environment, University Kebangsaan Malaysia, 43600 UKM Bangi,

Selangor, Malaysia 
Am. J. Applied Sci., 9 (2): 186-195, 2012

Internet speed, streaming video and other demanding applications (Kayne, 2011).

\section{MATERIALS AND METHODS}

The Internet utilizes a backbone of fiber optic cables capable of delivering incredible bandwidth. This inherent ability makes the Internet a prime source for advancing network technologies that can be brought to the home or business. In next generation systems, it is likely that data traffic will dominate and the trend is towards Internet Protocol (IP) based networks will continue. The trend towards IP based data services means that the Data Link Layer (DLL) used must be able to support IP and transport the resulting packets efficiently (Hassan et al., 2008). Most subscribers, however, $\log$ on to this network through copper lines with limited capacity. This creates a bottleneck for advancing technologies that increasingly require greater bandwidth. FTTH bridges this gap. Fiber optic cables are made of glass fiber that can carry data at speeds exceeding 2.5 gigabits per second (gbps). FTTH services commonly offer a fleet of plans with differing speeds that are price dependent. At the lower end of the scale, a service plan might offer speeds of 10 megabits per second (mbps), while typical Digital Subscriber Line (DSL) service running on existing copper lines is 1.5 mbps. A more expensive FTTH plan might offer data transfer speeds of over 100 mbps that's about 66 times faster than typical DSL Computer Big Lab, 2010.

FTTH can be installed as a point-topoint architecture, or as a Passive Optical Network $(\mathrm{PON})$. The former requires that the provider have an optical receiver for each customer in the field. PON FTTH utilizes a central transceiver and splitter to accommodate up to 32 clients. Optical electric converters, or OECs, are used to convert the signals to interface with copper wiring where necessary (Heard, 2008).

Some another usage of optics is optical sensor. The use of the fiber optic sensor technology makes it possible to realize continous, real-time and automatic health monitoring for transportation infrastructure. The technology offers several advantages such as: Minimized downtime, avoidance of catastrophic failure and reduction in maintenance labor. In addition, any new design of the infrastructure may encompass fiber optic sensors to make smart structures (Chang and Mehta, 2010).

FTTH network which is based on Passive Optical Network (PON) comprises of 3 main components which are Optical Line Terminal (OLT), optical splitter and Optical Network Unit (ONU). Optical splitter determines the size of network user it covers. Although FTTH-PON is an ideal network, a lot of new fiber has the potential to be developed. This study discussed one of the latest device which allow two fiber to be connected and it is called connector.

A wide variety of optical fiber connectors and adapters has evolved for numerous different applications including in FTTH network. Their uses range from simple single-channel fiber-to-fiber connectors in a benign location to multichannel connectors used in harsh military field environments. Some of the principal requirements of a good connector design are low coupling losses, interchangeability, ease of assembly, low environment sensitivity, low cost and reliable construction and ease of connection. So, we are going to do the experiment about influence of connectors and adapters in performance of FTTH network (Randy et al., 2005).

Now, many researchers (Pirich et al., 2008; Martins et al., 2009; Jones and Thiraviam, 2010) have studied and analysis the fiber optic connectors. Connectors and adaptors are very needed to perform the optical network operation. Some researchers have done experiments about connector (Suzuki et al., 1986; Satake et al., 1986; Nagasawa et al., 1991; Iwano et al., 1992; Young et al., 1989; Parzygnat, 1987; Sankawa et al., 1986). There are four typical contact type of connectors. They are perpendicular and oblique endface connectors employing either physical contact or contact via index matching material. The oblique endface connector is very effecti to reduce the reflection (Suzuki et al., 1986; Nagasawa et al., 1991; Young et al., 1989). The physical contact type connector has also been analysis to improve the return loss.

These connectors, without index-matching, are developed for intra-office usage and on premises where frequent reconnections are neede. On the other hand, the perpendicular endface connectors with index-matching are used in outside plants where frequent reconnections are unnecessary but low cost joints are required.

Mechanical alignment can be a major problem when joining two fibers. Radiation losses result from mechanical misalignments because the radiation cone of the emitting fiber does not match the acceptance cone of the receiving fiber. The three categories of mechanical misalignment are end separation, lateral offset and angular offset as shown in Fig. 1 (Uhing et al., 1990).

Theory and concepts: In fiber optic communication, the optical accessories such as connectors, couplers, switches, splices and multiplexing devices are essential elements to ensure a successful operation of fiber links and networks. From a selection set of device components, analysis or simulation has to be carried out to determine whether the system is designed within the requirements. In general, fiber optic cables offer many variations in the connectorization of the cord. 
Am. J. Applied Sci., 9 (2): 186-195, 2012

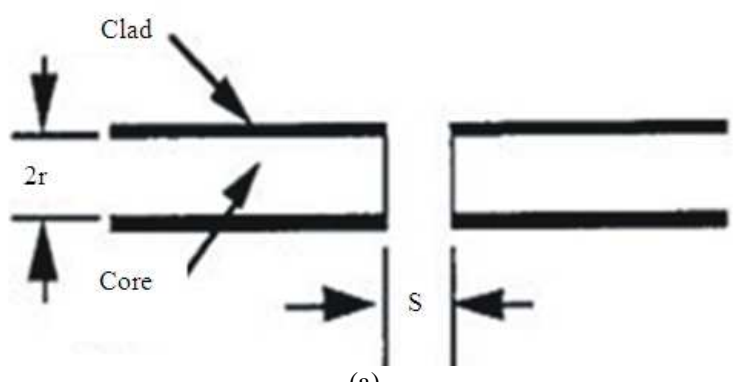

(a)

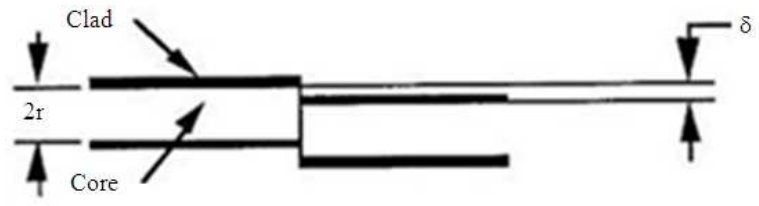

(b)

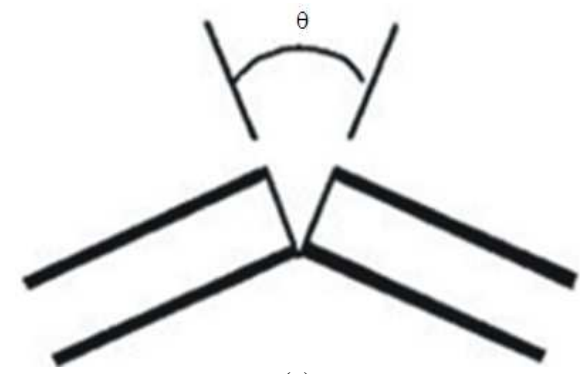

(c)

Fig. 1: Mechanical misalignments that can occur between two joined fibers (Uhing et al., 1990), (a) End separation (b) Lateral offset (c) Angular offset

A connector on one end is called a piftail, a cable with connectors on each end is called a patch cord or jumper and a multi-fiber cable with a single connector on one end and multiple connectors on the other can be called a breakout. Basically besides fiber optic cable, fiber optic connector is also a device mounted to the end of light source or optical receiver, which mates to a similar device to couple light into and out of optical fibers, Fiber optic connectors provide an impermanent connection between two fiber optic components and can be removed and reconnected in a new configuration if desired. Compared to an electrical connector which the contact of conductors is enough to pass the signal, an optical connection is different where it must be precision-aligned to permit the light to pass from one optical fiber to another with minimal loss. To join two fiber optic cables, an adaptor is used in between the two fiber optic connectors. In addition, fiber optic connectors are joined to fiber optic cables by a process called termination. The connector endfaces will first being polished to lessen the amount of light lost at the interface between two connectors. The polished connectors then undergo a series of tests that certify the optical performance of the connector.

In fact, there is attenuation in connectors and adaptors. Attenuation, a reduction in the transmitted power has long been a problem for the fiber optics community. The increase in data loss over the length of a fiber has somewhat hindered widespread use of fiber as a means of communication. There are three main sources of attenuation, i.e., absorption, scattering and dispersion. Absorption occurs when the light beam is partially absorbed by lingering materials such as water and metal ions, within the core of the fiber as well as in the cladding. Scattering occurs when atoms or other particles within the fiber spread the light. This process differs with absorption since for the most part, foreign particles on the fiber are not absorbing the light, but the light signal bounces off the particle rather than the fiber's wall and spreads the signal in another direction. There are three types of dispersion, i.e. the material dispersion which results from the fact that the refractive index of the fiber medium varies as a function of wavelength, waveguide dispersion which is very similar to material dispersion except it depends on the shape, design and chemical composition of the fiber core and finally the modal dispersion where the modes are not be received at the same time and the signal will be distorted or even lost over long distances since the rays of the light pulse are not perfectly focused together into one beam and cause each mode of light travels a different path.

There are several tests can be done to measure the system performance. One of it is named the eye pattern, which is the appearance of the signal on an oscilloscope. As shown in Fig. 2, the pattern resembles an eye. Figure 2a shows an idealized eye diagram where the pulses exhibit little dispersion and jitter. The decision times and decision levels are shown. Figure $2 b$ shows a typical eye diagram which will be obtained in practice.

The eye pattern reveals the following:

- Width of the eye, which shows the maximum time interval without inter symbol interference

- Height if the eye, which shows the noise margin

- System rise time is easily measured

- Nonlinearities in the system will result in an asymmetry in the eye pattern

Besides, the performance of data transmission can also be quantified by the Bit Error Rate (BER). The BER is the fraction of transmitted data that is mistakenly decoded by the receiver. 


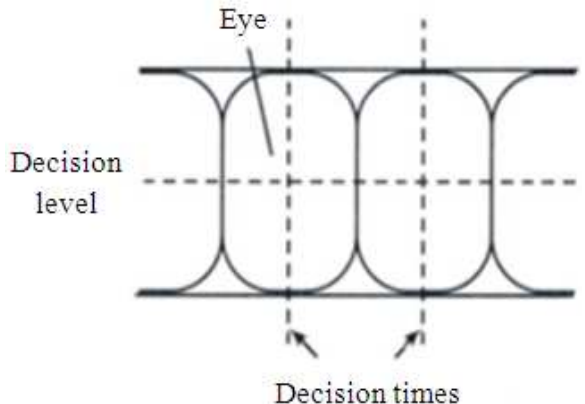

(a)

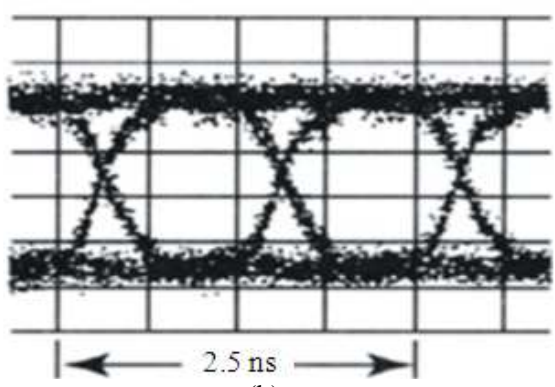

(b)

Fig. 2: Eye pattern (Hagans and Paulson, 2001)

BER is a function of the system quality factor, Q. The quality factor is an electrical domain measure of the ratio of the separation between digital states to the noise associated with the states. Both the numerator and the denominator of $\mathrm{Q}$ can be partitioned into contributions whose sources are objects of system design. Examples include accumulated optical noise generated by optical amplifiers, signal optical power, Polarization-Dependent Loss (PDL) and Polarization Mode Dispersion (PMD), receiver and transmitter transfer function, net dispersion and nonlinear propagation noise and distortion (Hagans and Paulson, 2001).

\section{RESULTS}

The actual attenuation of connector and adaptor are tested by using Multifunction Loss Tester. First two $1 \mathrm{~m}$ corning optical fiber with a connector at each end is tested by using the Loss Tester separately as shown in Fig. 4. Three types of wavelength are used as the source to test the attenuation of the fiber, i.e. 1310 and 1490$1550 \mathrm{~nm}$. Before the test is carried out, the endfaces of the connectors are first polished to lessen the amount of light at the interface between two connectors. To carry out the measurement of the connectors, first the source and destination of the Loss Tester are set to the same wavelength value, for example $1310 \mathrm{~nm}$.

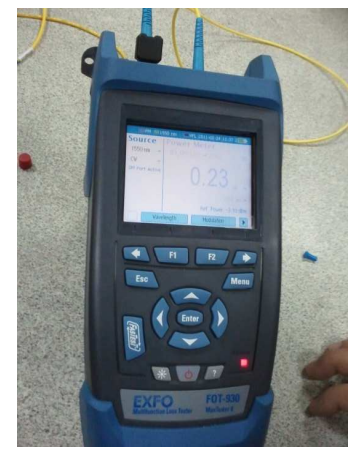

Fig. 3: The attenuation of $1 \mathrm{~m}$ corning optical fiber is tested by using multifunction loss tester

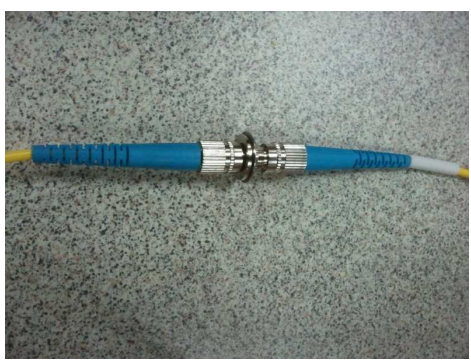

Fig. 4: Two connectors are joined by using an adaptor

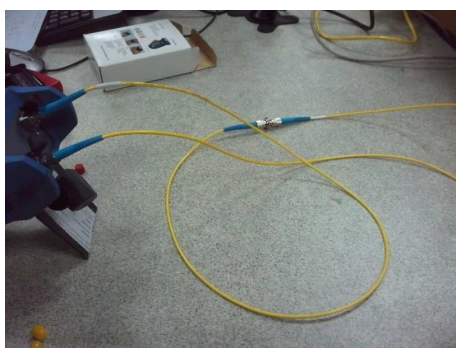

Fig. 5: The attenuation of both $1 \mathrm{~m}$ corning optical fibers with adaptor is tested by using multifunction loss tester

Then the attenuation is obtained and recorded. The steps are repeated for wavelength 1490-1550 nm. The attenuation of each fiber and connector with respective wavelength is recorded in Table 1.

Figure 3 shows the measurement of attenuation of $1 \mathrm{~m}$ corning optical fiber using optical power meter. From this figure, it shows that the attenuation of $1 \mathrm{~m}$ corning connector is $0.23 \mathrm{~dB}$.

Multifunction loss tester: Then, both the $1 \mathrm{~m}$ corning optical fiber are joined together by an adaptor and connected to the Multifunction Loss Tester as shown in Fig. 5. 


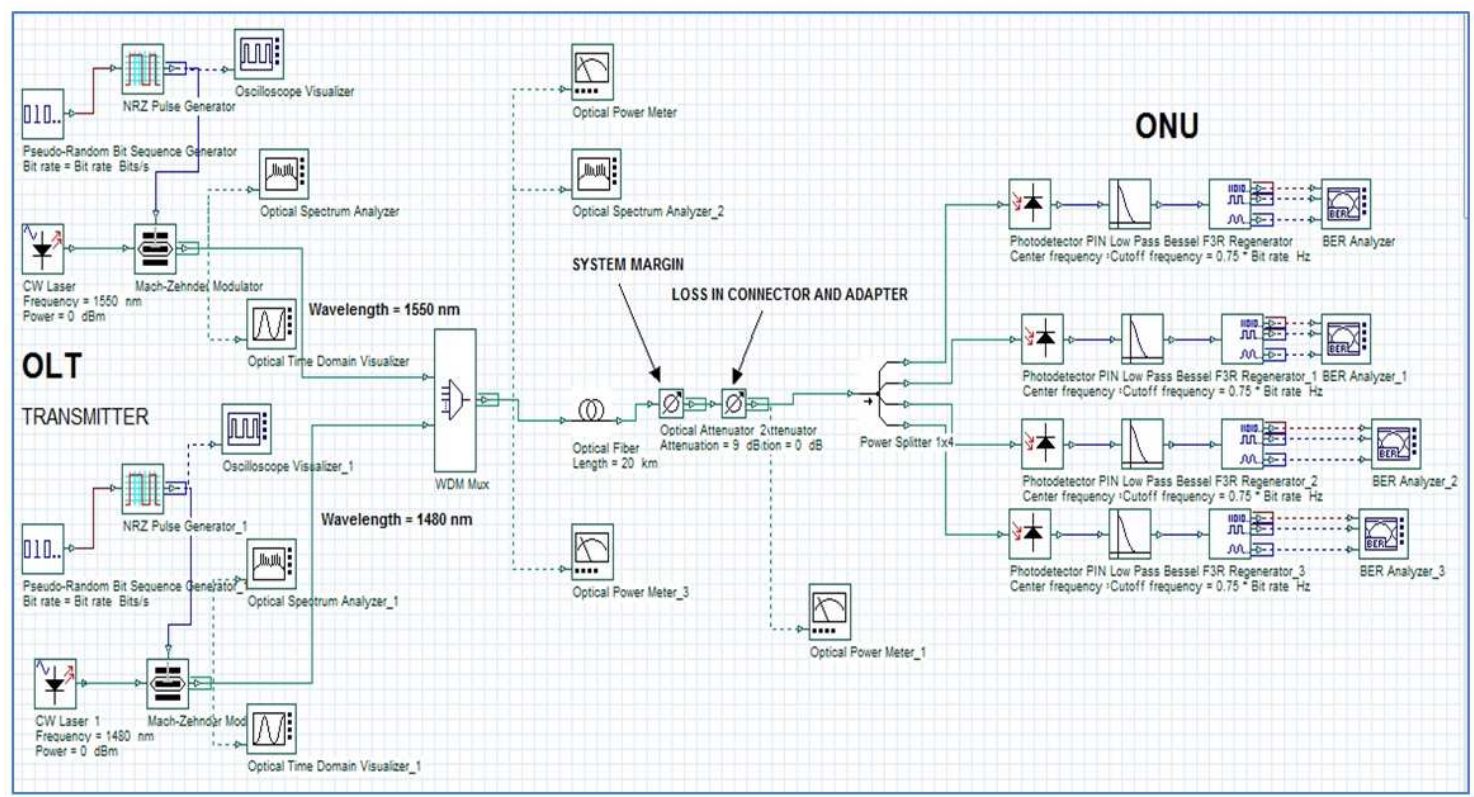

Fig. 6: FTTH platform

Table 1: Attenuation of $1 \mathrm{~m}$ corning fiber and combination of two $1 \mathrm{~m}$ corning fibers

\begin{tabular}{llll}
\hline & $\begin{array}{l}\text { Attenuation } \\
\text { corning fiber }\end{array}$ & $\begin{array}{l}\text { Attenuation } \\
\text { corning fiber } \\
\text { corning fiber } 2\end{array}$ & $\begin{array}{c}\text { Attenuation }(\mathrm{nm}) \\
\text { corning fiber 1 } \\
\text { Wavelength }\end{array}$ \\
$1(\mathrm{~dB})$ & $2(\mathrm{~dB})$ & 0.70 \\
\hline 1310 & 0.51 & 0.40 & 0.29 \\
1490 & 0.23 & 0.03 & 0.26 \\
1550 & 0.09 & 0.03 & 0.03 (dB) \\
\hline
\end{tabular}

The attenuation of the combined fibers is tested by using $1310 \mathrm{~nm}, 1490-1550 \mathrm{~nm}$ wavelength as the source and the result is recorded in Table 1.

Simulation: In order to measure the BER (Bit Error Rate) and the power loss in optical fiber communication, a simple simulation is carried out by using software OptiSys version 7.0. In this software, a various type of simulation can be done by creating the circuit using the entire device and components available in the software library. To test the effect of attenuation caused by connector and adaptor, a FTTH platform is created as shown in Fig. 6.

In the transmitter part, two different wavelengths are used, i.e. $1490-1550 \mathrm{~nm}$. Both the channels of wavelength will then enter a WDM multiplexer which is used to combine two channels of wavelength together into one single optical fiber. To view the shape of the wavelength, a device called optical spectrum analyzer is used. The shape of the wavelength is shown in Fig. 7 and 8.

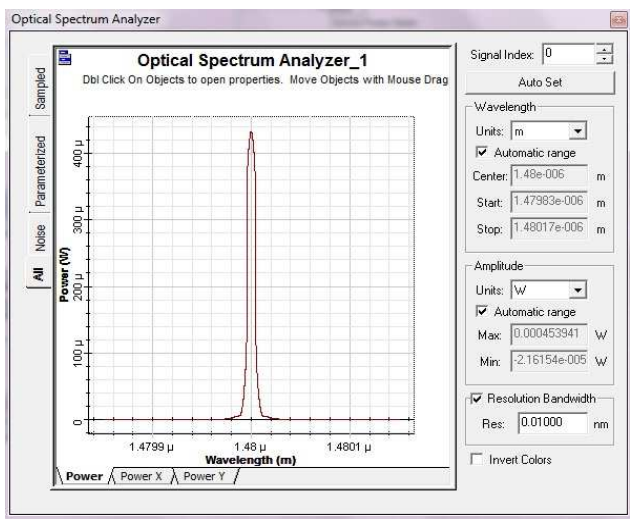

Fig. 7: Wavelength of $1480 \mathrm{~nm}$ signal

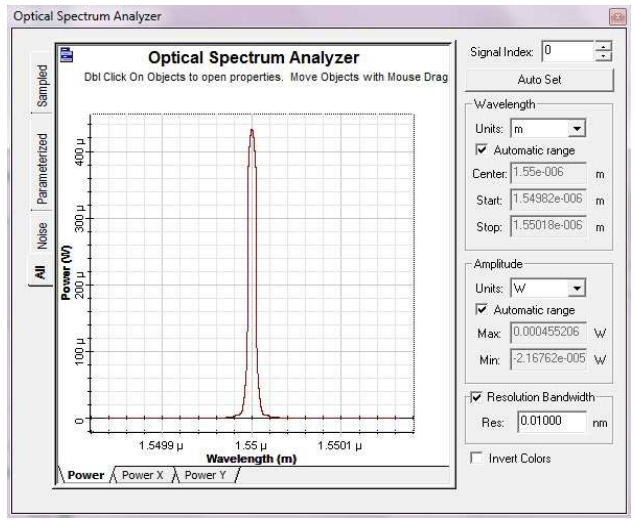

Fig. 8: Wavelength of $1550 \mathrm{~nm}$ signal 
Am. J. Applied Sci., 9 (2): 186-195, 2012

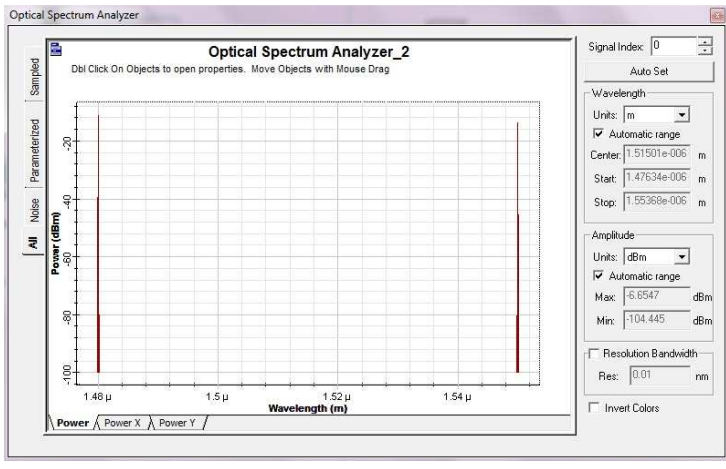

Fig. 9: Wavelength in the optical fiber

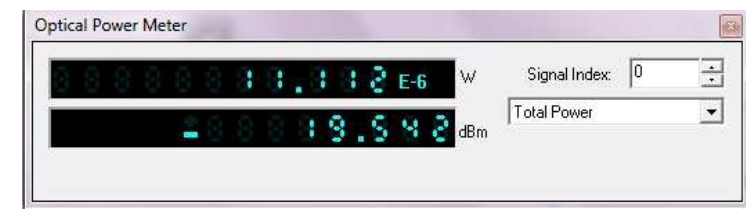

Fig. 10: Power measured after the splitter $1 \times 4$

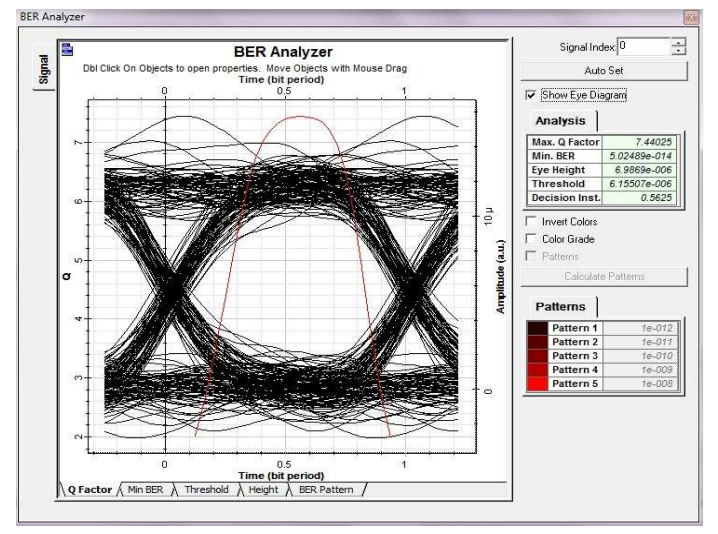

Fig. 11: Eye diagram for attenuator of $0 \mathrm{~dB}$

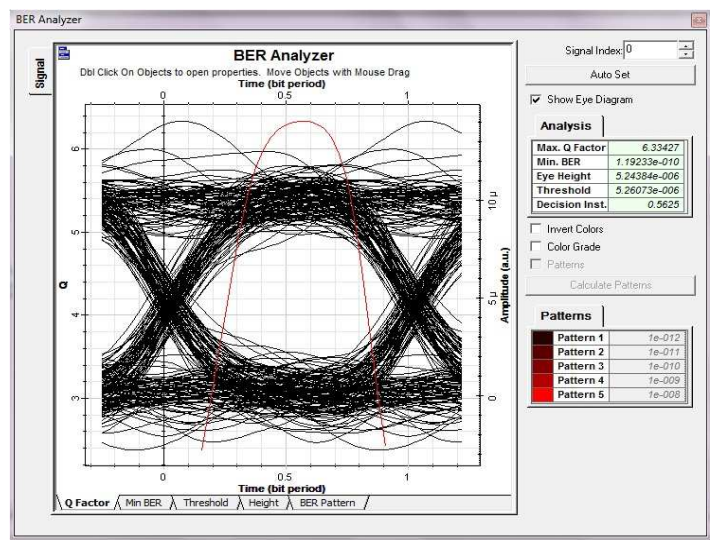

Fig. 12: Eye diagram for attenuator of $0.7 \mathrm{~dB}$

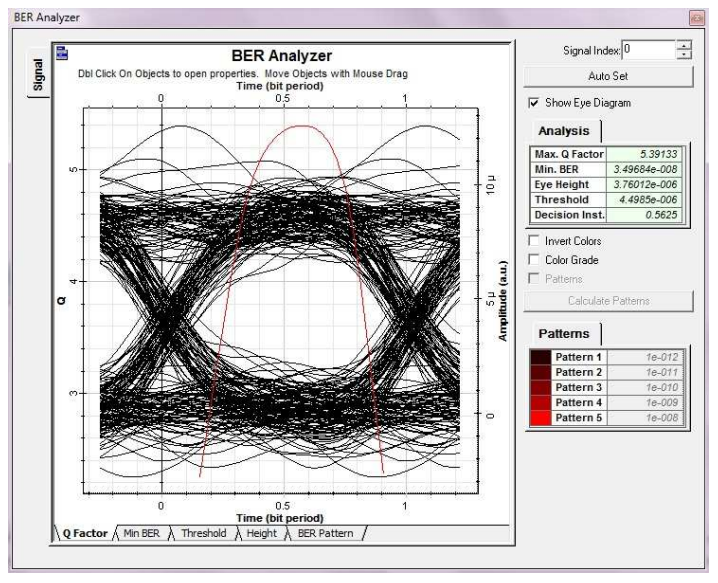

Fig. 13: Eye diagram for attenuator of $1.4 \mathrm{~dB}$

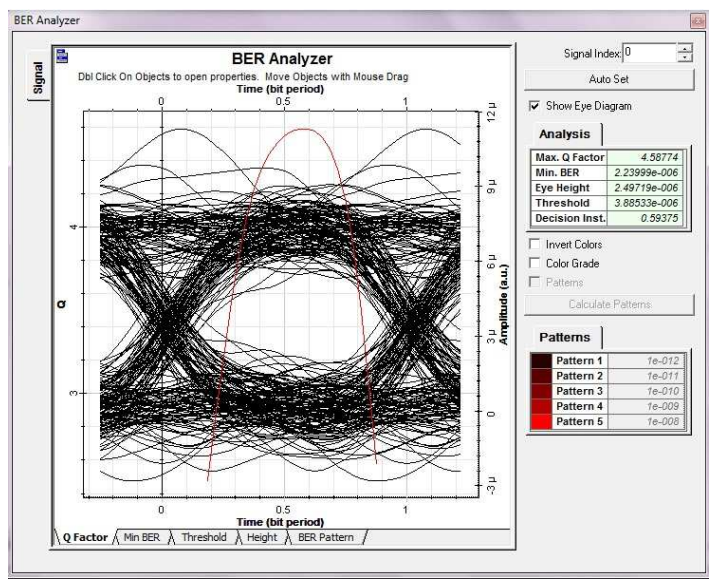

Fig. 14: Eye diagram for attenuator of $2.1 \mathrm{~dB}$

Using only single cable reduces the cost and budget in the communication since the price of optical fiber is high. The wavelength combined by the WDM Mux can be simulated by using the Optical Spectrum Analyzer_2. The result is shown in the Fig. 9.

Figure 10 shows the power meter used to measure the y Optical Network Unit (ONU). Due to the losses along the transmission, the signal received may not be exactly the same as the transmitted signal. In this simulation, a BER analyzer is used to measure the Bit Error Rate of the signal. The shape of the eye diagram of the BER is changed due to the value of the attenuator for the pair of connectors with the adapter. The values of the attenuator used are within 0 and $5.6 \mathrm{~dB}$. The value of $0 \mathrm{~dB}$ represent that there are no connectors and adapter in the fiber and the fiber act as an ideal fiber. The value of $0.7 \mathrm{~dB}$ means that there is a pair of connectors with adapter in the fiber optic. The result of the BER with different attenuations is shown in Fig. 11-19. 
Am. J. Applied Sci., 9 (2): 186-195, 2012

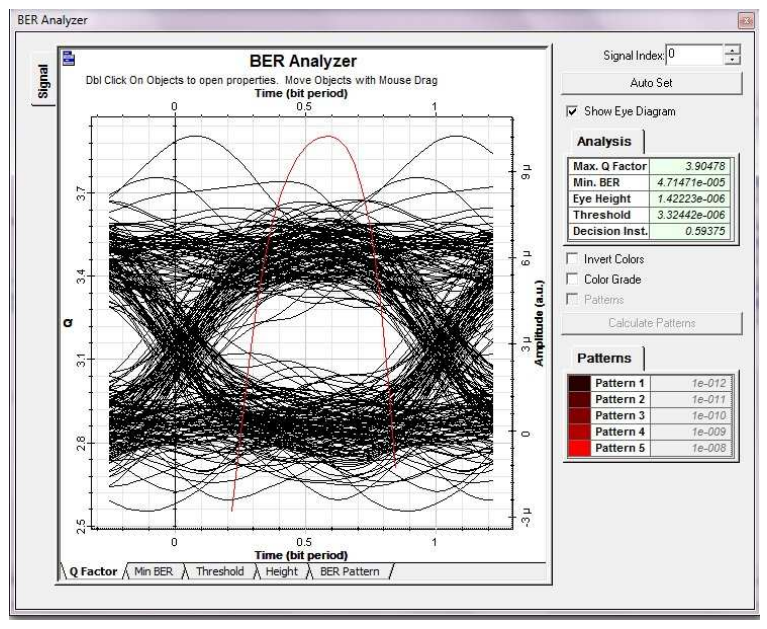

Fig. 15: Eye diagram for attenuator of $2.8 \mathrm{~dB}$

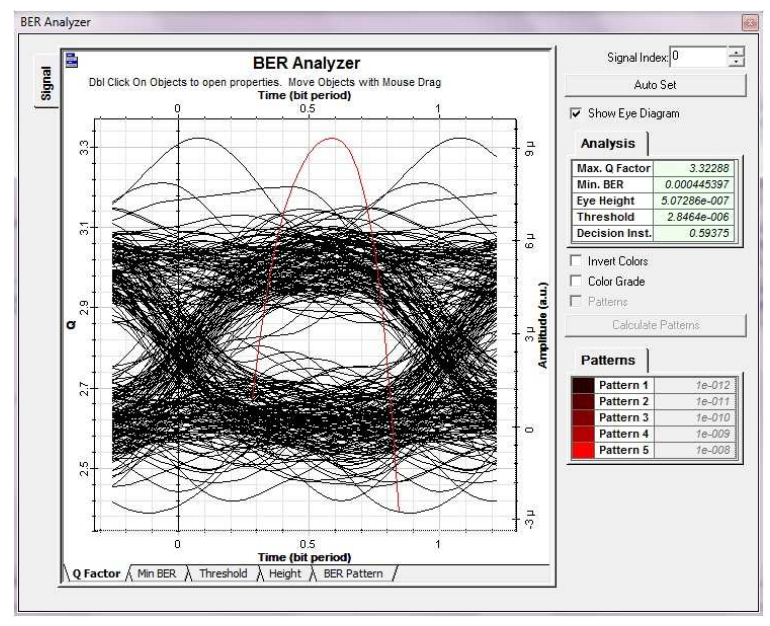

Fig. 16: Eye diagram for attenuator of $3.5 \mathrm{~dB}$

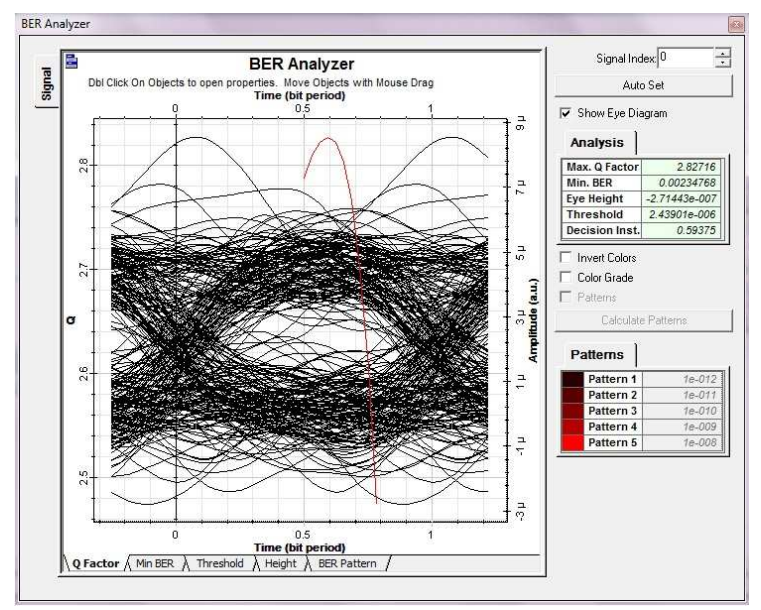

Fig. 17: Eye diagram for attenuator of $4.2 \mathrm{~dB}$

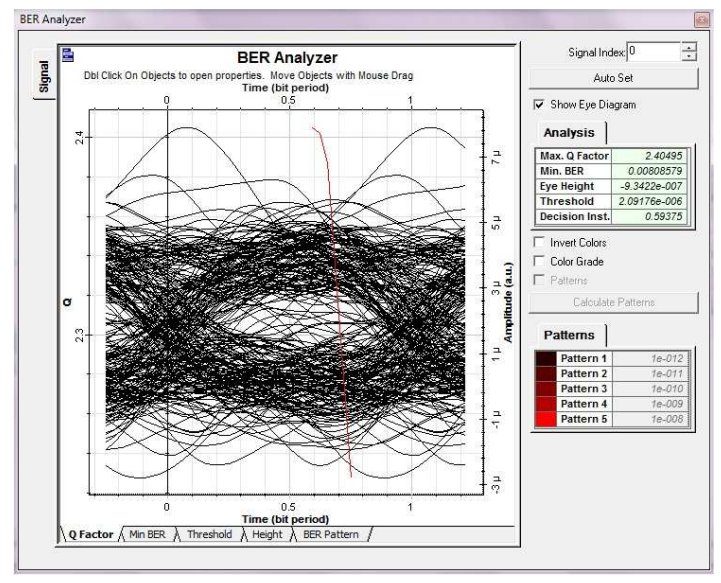

Fig. 18: Eye diagram for attenuator of $4.9 \mathrm{~dB}$

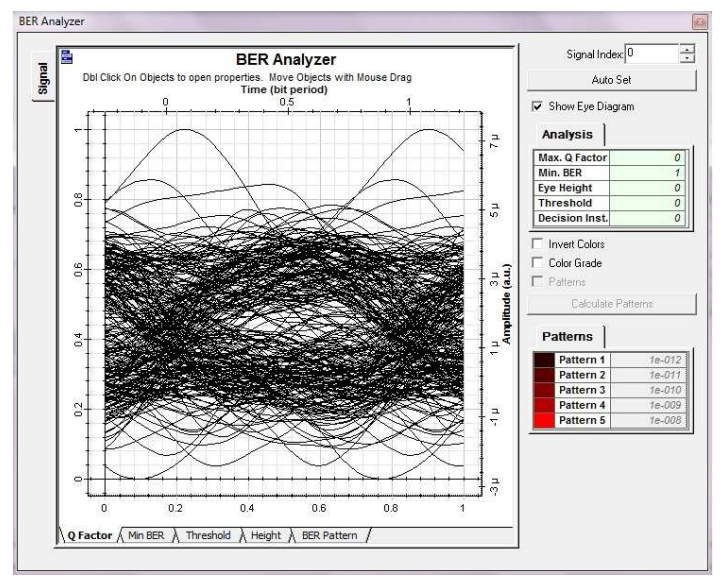

Fig. 19: Eye diagram for attenuator of $5.6 \mathrm{~dB}$

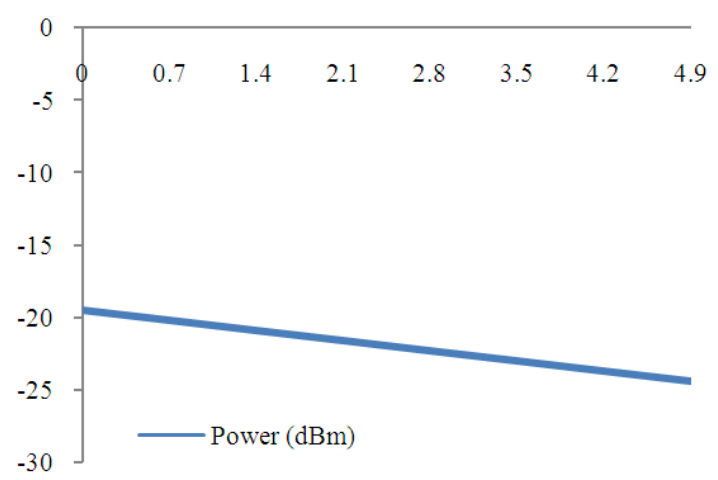

Fig. 20: Graph of power received against attenuation

The result of the simulation is summarized in Table 2 including the Power, Max Q factor, Min BER, Eye height, Threshold and Decision Inst. The effect of attenuation in those parameters is shown in Fig. 20-25. 
Am. J. Applied Sci., 9 (2): 186-195, 2012

Table 2: Data from BER analyzer

\begin{tabular}{llllllll}
\hline Attenuator $(\mathrm{dB})$ & Connector (unit) & Power $(\mathrm{dBm})$ & Max Q factor & Min BER & Eye height & Threshold & Decision inst \\
\hline 0.7 & 1 & -20.242 & 6.334 & $1.192 \mathrm{E}-10$ & $5.243 \mathrm{E}-06$ & $5.2600 \mathrm{E}-06$ & $5.626 \mathrm{E}-01$ \\
1.4 & 2 & -20.942 & 5.391 & $3.496 \mathrm{E}-08$ & $3.760 \mathrm{E}-06$ & $4.498 \mathrm{E}-06$ & $5.625 \mathrm{E}-01$ \\
2.1 & 3 & -21.642 & 4.587 & $2.239 \mathrm{E}-06$ & $2.497 \mathrm{E}-06$ & $3.885 \mathrm{E}-06$ & $5.937 \mathrm{E}-01$ \\
2.8 & 4 & -22.342 & 3.904 & $4.714 \mathrm{E}-05$ & $1.422 \mathrm{E}-06$ & $3.324 \mathrm{E}-06$ & $5.937 \mathrm{E}-01$ \\
3.5 & 5 & -23.042 & 3.322 & $4.453 \mathrm{E}-04$ & $5.072 \mathrm{E}-07$ & $2.846 \mathrm{E}-06$ & $5.937 \mathrm{E}-01$ \\
4.2 & 6 & -23.742 & 2.827 & $2.347 \mathrm{E}-03$ & $-2.714 \mathrm{E}-07$ & $2.439 \mathrm{E}-06$ & $5.937 \mathrm{E}-01$ \\
4.9 & 7 & -24.442 & 2.404 & $8.0859 \mathrm{E}-03$ & $-9.342 \mathrm{E}-07$ & $2.091 \mathrm{E}-06$ & $5.937 \mathrm{E}-01$ \\
\hline
\end{tabular}

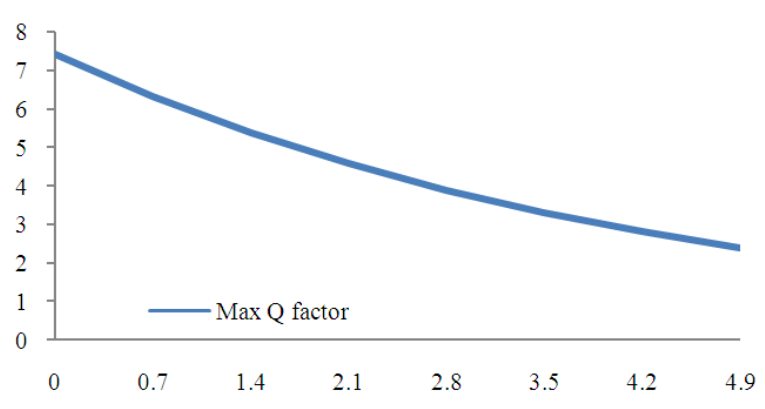

Fig. 21: Graph of maximum Q-factor against attenuation

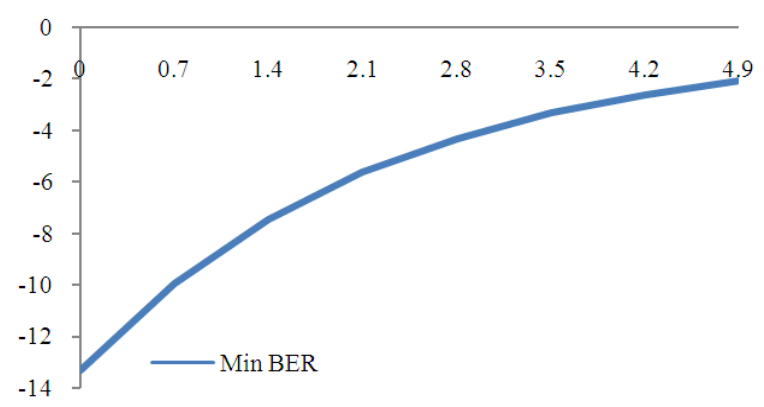

Fig. 22: Graph of minimum BER against attenuation

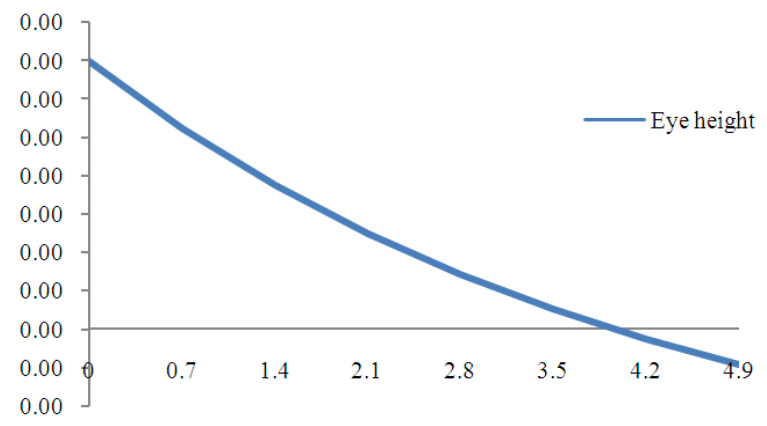

Fig. 23: Graph of eye height against attenuation

The length of the optical fiber used in this simulation is $20 \mathrm{~km}$. The type of optical fiber used is the Corning Optical Fiber. From the data sheet and some mathematical calculation, the value of the power loss in the fiber that is about $0.8 \mathrm{~dB}$.

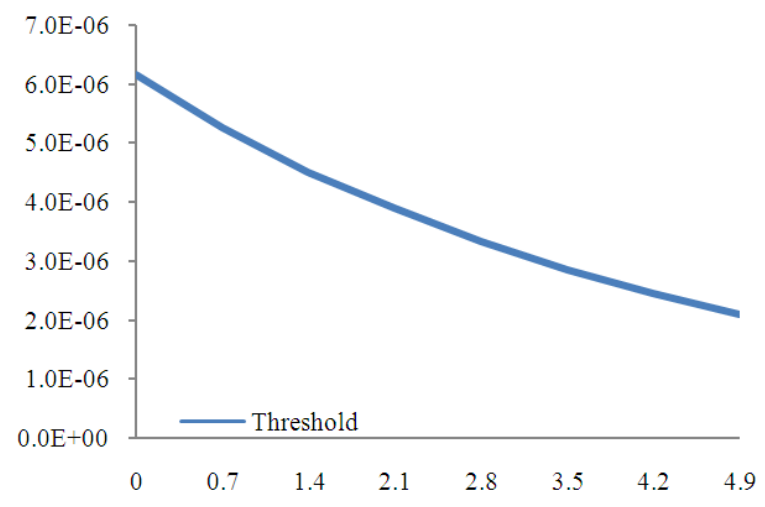

Fig. 24: Graph of threshold against attenuation

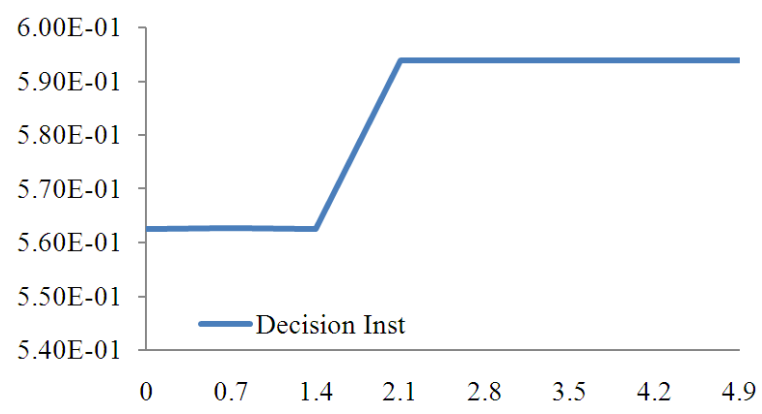

Fig. 25: Graph of decision inst against attenuation

In link power budget, system margin is one of the parameter that has to be considered. System margin or link margin normally provided in analysis to allow the component aging, temperature fluctuations and losses arising from components that might be added at future date. In this simulation, the value of system margin is $9 \mathrm{~dB}$.

In the real application, along the fiber, there are a number of connectors and adapters along the fibers which will also contribute to the losses in power level and affect the quality of the transmitted signal. In this simulation, an attenuator is used to represent the losses in connector and adapter. In our experiment, the value of the connectors and adapter measured by using the Multifunction Loss Tester is $0.7 \mathrm{~dB}$ and this value is used in this simulation. 


\section{DISCUSSION}

The attenuation on the connector is caused mainly by existence of impurities in the connector, less perfect connection, scattering of beam and others. These causes the parameter such as Power received, Q-factor, minimum BER and also the eye-height to change. Changes in these parameters also affect the performance at the user end. It is very critical that causes of attenuation to be eliminated.

Effect of attenuation on the power received: Figure 20 shows is the graph of power received $(\mathrm{dBm})$ versus the attenuation. It can be observed that the power received is greatly affected by the attenuation. The greater the attenuation, the power received decreases. The power received varied directly proportionally with the attenuation. It can be see that with the increase of 1 $\mathrm{dB}$ of attenuation, the power received decrease by $1 \mathrm{~dB}$.

The Power received decreased because there are losses in the connector. Absorption of optical energy is done by the tiny impurities in the connector. This means that the connector is not clean and there is some dirt. The dirt particle in turn spreads the signal to other direction which causes the loss. The more the connector, the power received will also decrease. The value observed from the experiment is almost the same as the value of theory which is approximately $1 \mathrm{~dB}$ loss.

Effect of attenuation on q-factor: Figure 21 is the graph of Maximum Q-Factor or factor Q plotted against the attenuation. From here, we can see the maximum $\mathrm{Q}$ factor is actually changes inversely as the attenuation increase. It can be observed that initially when the attenuation is $0 \mathrm{~dB}$ the Maximum Q-Factor is 7.44025. As attenuation increases, the maximum $Q$ factor decreases to $4.9 \mathrm{~dB}$ the maximum $\mathrm{Q}$ factor changes to 2.40495. Q-Factor is used to specify the performance of receiver since it is related to SNR ratio. As Q-factor varies, BER also varies.

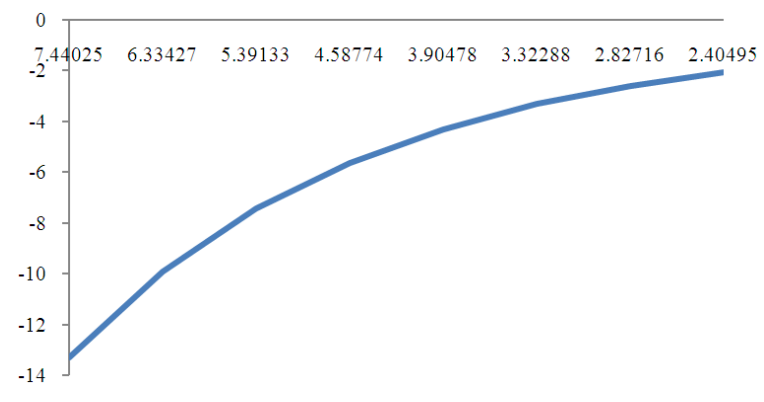

Fig. 26: Graph of min BER against max Q-factor
As the attenuation represent the loss in connector which causes the performance of receiver to changed. This means that the connector causes the performance of receiver to be decreases as the more connector is used in the system.

Effect of attenuation on minimum BER: Figure 22 shows that the effect of attenuation of connector on the minimum BER of the system. At initial point where the attenuation is $0 \mathrm{~dB}$ the bit error rate is $5.02489 \mathrm{E}-14$.

As attenuation increase by little, the BER increase greatly at a point around where the attenuation is $0.8 \mathrm{~dB}$ where the increase reaches its maximum value which is around $1.2 \mathrm{E}-01$ and then it drops significantly. After $1.3 \mathrm{~dB}$ of attenuation, the value min BER change little with the attenuation.

This means that the bit error rate is affected by attenuation in small range only. After $1.3 \mathrm{~dB}$ the BER have little changes. This means for attenuation of $0.8 \mathrm{~dB}$ it has the highest rate of having an error.

Figure 26 shows how the Min BER is affected by the Q-factor. The relation of BER and Q-factor is that from the maximum point, the increase in the $\mathrm{Q}$-factor, will caused the decrease in the BER.

Effect of attenuation on eye height: Figure 23 shows the result of the eye height against the attenuation. It can be deduced that the eye height of the eye pattern is changing inversely with the attenuation. As attenuation increases the eye height also increases. When the attenuation is $0 \mathrm{~dB}$ or no losses in connector the eye eight is $6.9869 \times 10^{-06}$.

Eye height represents noise margin of the connector. The higher the noise margin lesser the signal is sensitive to noise. This is true because at $0 \mathrm{~dB}$ or no loss, the Eye height is the highest which mean the signal at $0 \mathrm{~dB}$ will be less sensitive to noise.

\section{CONCLUSION}

As mentioned above attenuation, is the reduction in the transmitted power and there are three main sources of attenuation which include absorption, scattering and dispersion. The main caused for the attenuation in connector is absorption where of optical energy is absorbed by tiny impurities in the connector.

In this experiment, the main objective is to carry out test, measurement and simulation to compare the affect of attenuation to a few parameter such as power received using a optical power meter and also using BER analyser to get the value for, Q-factor, minimum BER and also the eye-height which is at the consumer side (ONU). 
From the result it can be concluded that, the greater the attenuation, the greater the decrease in power received. Besides, it also affects the Q-factor of the system where as the attenuation increase, the maximum Q-factor decreases. As for the minimum BER, minimum BER changes as the attenuation increase initially, after a maximum value it decreases as the attenuation increases. Last but not least, for the eye height, as the attenuation increase the eye height decreases.

\section{ACKNOWLEDGMENT}

This research study was supported by the Ministry of Science, Technology and Innovation (MOSTI), Government of Malaysia, through the National Science Fund (e-Science) 01-01-01-SF0493 and Ministry of Higher education with grant number UKM-KK-03FRGS0122-2010.

\section{REFERENCES}

Chang, C. and R. Mehta, 2010. Fiber optic sensors for transportation infrastructural health monitoring. Am. J. Eng. Applied Sci., 3: 214-221. DOI: 10.3844/ajeassp.2010.214.221

Hagans, A. and K. Paulson, 2001. Attenuation in fiber optics. University of North Carolina at Charlotte.

Hassan, R., J. Irvine and I. Glove, 2008. Design and analysis of virtual bus transport using synchronous digital hierarchy/synchronous optical networking. J. Comput. Sci., 4: 1003-1011. DOI: 10.3844/jcssp.2008.1003.1011

Iwano, S., R. Nagase, K. Kanayama, E. Sugita, K. Yasuda and Y. Ando, 1992. Compact and selfretentive multi-ferrule optical backpanel connector. J. Lightw. Technol., 10: 1356-1362. DOI: 10.1109/50.166776

Jones, R.T. and A. Thiraviam, 2010. Reliability of Fiber Optic connectors. OCEANS, DOI: 10.1109/OCEANS.2010.5664452

Kayne, R., 2011. What is FTTH? Conjecture Corporation.

Martins, A., A.M. Rocha and P.S. Andre, 2009. High power effects on fiber optic connectors. Proceedings of the SBMO/IEEE MTT-S International Microwave and Optoelectronics Conference, Nov. 3-6, IEEE Xplore Press, Belem, pp: 456-458. DOI: 10.1109/IMOC.2009.5427546

Heard, I.B., 2008. Availability and cost estimation of secured FTTH architectures. Proceedings of the International Conference on Optical Network Design and Modeling, Mar. 12-14, IEEE Xplore Press, Vilanova i la Geltru, pp: 1-6. DOI: 10.1109/ONDM.2008.4578390
Nagasawa, S., Y. Yokoyama, F. Ashiya and T. Satake, 1991. A high-performance single-mode multifiber connector using oblique and direct endface contact between multiple fibers arranged in a plastic ferrule. IEEE Photon. Technol. Lett., 3: 937-939. DOI: $10.1109 / 68.93269$

Parzygnat, W.J., 1987. A high fiber density optical connector for use in electronic packaging systems. Proceedings of the SPIE Conference on Digital Optical Computing, Jan. 13-14, Los Angeles, CA, USA., pp: 217-221.

Pirich, R., T. Innes and P. Anumolu, 2008. Fiber-optic requirements for advanced platform integration. Proceedings of the IEEE Avionics, Fiber-Optics and Photonics Technology Conference, Sept. 30Oct. 2, IEEE Xplore Press, San Diego, CA., pp: 4748. DOI: 10.1109/AVFOP.2008.4653169

Randy, R., J. Gniadek and Y. Lu, 2005. Outside plant connections you can rely on. Proceedings of the FTTH Conference, (FTTHC' 05), ADC Telecommunications, Inc., pp: 1-8.

Sankawa, I., T. Satake, N. Kashima and S.N Members, 1986. Methods for reducing the fresnel reflection in an optical-fiber connector with index matching material. Electron. Commun. Japan (Part I: Commun.), 69: 94-102. DOI: 10.1002/ecja.4410690111

Satake, T., S. Nagasawa and R. Arioka, 1986. A new type of demountable plastic-molded single-mode multifiber connector. J. Lightw. Technol., 4: 12321236. DOI: $10.1109 /$ JLT.1986.1074860

Suzuki, N., M. Saruwatari and M. Okuyama, 1986. Low insertion-and high return-loss optical connectors with spherically convex-polished end. Electronics Letters, 22: 110-110. DOI: 10.1049/el:19860078

Uhing, J., S. Thomas and C. Christodoulou, 1990. A statistical approach for estimating the loss contribution of concatenated connectors in fiberoptic links. Proceedings of the IEEE 1990 National Aerospace and Electronics Conference, May 21-25, IEEE Xplore Press, Dayton, OH , USA., pp: 239245. DOI: $10.1109 /$ NAECON.1990.112772

Young, W.C., V. Shah and L. Curtis, 1989. Loss and reflectance of standard cylindrical-ferrule singlemode connectors modified by polishing a $10^{\circ}$ oblique endface angles. IEEE Photon. Technol. Lett., 1: 461-463. DOI: 10.1109/68.46050 